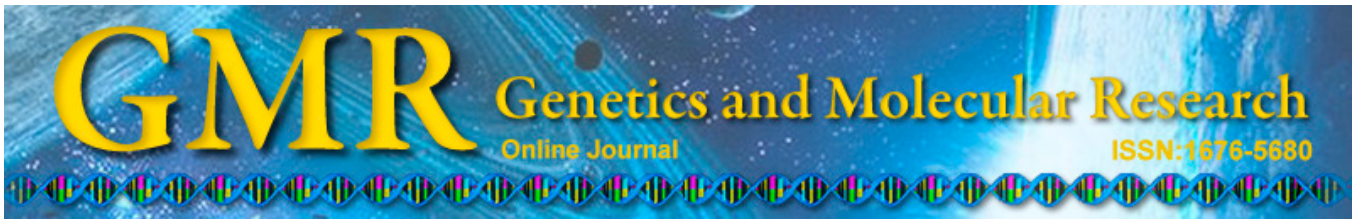

\title{
Study of the significance of iron deficiency indexes and erythrocyte parameters in anemic pregnant women and their newborns
}

\author{
L. Liu ${ }^{1 *}$, Y. Xiao ${ }^{2 *}$, B. Zou ${ }^{3}$ and L.L. Zhao ${ }^{1}$ \\ ${ }^{1}$ Department of Pediatrics, The Third Xiangya Hospital, \\ Central South University, Changsha, China \\ ${ }^{2}$ Neonatology Department, Guangzhou Women and Children's Medical Center, \\ Guangzhou, China \\ ${ }^{3}$ Department of Otolaryngology, \\ Children's Hospital of Chongqing Medical University, Chongqing, China \\ *These authors contributed equally to this study. \\ Corresponding author: B. Zou \\ E-mail: ZouBin929@163.com
}

Genet. Mol. Res. 14 (2): 3501-3508 (2015)

Received June 9, 2014

Accepted October 24, 2014

Published April 15, 2015

DOI http://dx.doi.org/10.4238/2015.April.15.14

\begin{abstract}
This study aimed to analyze the iron deficiency index and erythrocyte parameters in anemic pregnant women and their newborns, and explore their implications for anemia during pregnancy. Pregnant women (70) in the third trimester with hemoglobin $(\mathrm{Hb})<100$ $\mathrm{g} / \mathrm{L}$ who registered and delivered from June 2012-2013 were randomly selected as the observation group, 70 pregnant women at similar gestational ages with $\mathrm{Hb}>110 \mathrm{~g} / \mathrm{L}$ were selected as the control group, and 70 newborns delivered by women in each group were included in corresponding offspring observation and control groups, respectively. Periodic physical examinations were conducted on the infants, and blood samples were drawn from the women and infants at birth, 42 days, 4 months, and 6 months old for detection of $\mathrm{Hb}$ and soluble transferrin receptor (sTfR) levels. Pregnant women and their 6-month-old infants
\end{abstract}


in the observation group had significantly different $\mathrm{Hb}$ and sTfR levels compared to controls $(\mathrm{P}<0.01)$. There were no significant differences in $\mathrm{Hb}$ and sTfR levels of infants at birth, 42 days, and 4 months old $(\mathrm{P}>0.05)$. The detection rate of iron deficiency anemia (IDA) was significant, at $61.43 \%$ among 6-month-old infants in the observation group and $22.86 \%$ among controls $(\mathrm{P}<0.01)$. There were no significant differences in the detection rate of IDA among infants at birth, 42 days, and 4 months old between observation and control groups $(\mathrm{P}>0.05)$. Therefore, anemia during pregnancy is a major contributing factor of IDA and subclinical iron deficiency among 6-month-old infants.

Key words: Anemia during pregnancy; Iron deficiency index; Erythrocyte parameter

\section{INTRODUCTION}

Iron deficiency anemia (IDA) is a common and frequently occurring disease affecting human health. Pregnant women and infants belong to the population of those at high risk for IDA. The disease includes 3 periods: iron depletion (ID), iron deficient erythropoiesis (IDE), and IDA. IDA is a microcytic hypochromic anemia caused by decreased hemoglobin $(\mathrm{Hb})$ synthesis due to the body's lack of iron storage, and belongs to the most serious disease stage. During the ID and IDE periods, the iron storage in the human body is depleted, but the $\mathrm{Hb}$ content remains in the normal range; this situation is defined as subclinical iron deficiency (SID).

In pregnancy, IDA can not only affect the health of the pregnant woman, but can cause a lack of iron storage in the fetal liver, resulting in a greatly increased possibility of SID and IDA occurrence in infants (Cogswell et al., 2003). IDA during pregnancy is one of the most important reasons for higher incidence rates of SID and IDA in infants in China (Geelhoed et al., 2006). At present, the screening indexes of early iron deficiency in China are not yet fully developed, and $\mathrm{Hb}$ detection is currently only used for IDA screening. It is of little use for screening SID in other anemic periods of ID and IDE, resulting in a large number of infants with SID who cannot be efficiently discovered and treated. The subsequent development of IDA is also one of the important reasons for its increased incidence rate (Emamghorashi and Heidari, 2004; Grjibovski et al., 2004). To study the impact of anemia during pregnancy on IDA in newborns and infants, we conducted a prospective longitudinal monitoring of $\mathrm{Hb}$ and serum transferring receptor (sTfR) in anemic pregnant women, newborns, and infants, and report our findings thusly.

\section{MATERIAL AND METHODS}

\section{General information}

The study protocol was approved by GuangZhou Women and Children's Medical Center (GuangZhou, China). Informed consent was obtained from all subjects, that included 140 cases of pregnant women and their newborns and infants who had received prenatal care, delivered, and who had their infant physically examined at GuangZhou Women and Children's 
Medical Center from June 2012 to June 2013. Participants were then divided into observation and control groups, with each including 70 pregnant women. Participants in the observation group were 21 to 34 years of age, with an average of $27.54 \pm 8.92$ years; their gestational ages ranged from 28 to 40 weeks, with an average of $36.79 \pm 4.79$ weeks; the women in the control group were 22 to 34 years of age, with an average of $29.59 \pm 23$ years; their gestational ages ranged from 28 weeks to 40 weeks, with an average of $38.96 \pm 4.52$ weeks. There were 74 cases of male infants and 66 cases of female infants; birth weight ranged from 2657 to 3928 $\mathrm{g}$, with an average of $3452.93 \pm 38.96 \mathrm{~g}$, and birth height ranged from 45.89 to $60 \mathrm{~cm}$, with an average of $50.39 \pm 19.83 \mathrm{~cm}$. There was no statistically significant difference between the two groups of data $(\mathrm{P}>0.05)$. Among infants under 6 months of age, there were 46 cases of breast feeding, 14 cases of mixed feeding and 10 cases of artificial feeding in the observation group; there were 45 cases of breast feeding, 19 cases of mixed feeding and 6 cases of artificial feeding in the control group, and there was no significant difference between the two groups $(\mathrm{P}>0.05)$.

\section{Selection criteria}

Women in the third trimester of pregnancy $(\mathrm{N}=70)$ with $\mathrm{Hb}<100 \mathrm{~g} / \mathrm{L}$ were randomly selected as the observation group, and pregnant women $(\mathrm{N}=70)$ in the same gestational age ranges with $\mathrm{Hb}>110 \mathrm{~g} / \mathrm{L}$ were selected as the control group. Concurrently, the level of C-reactive protein in the blood was detected to exclude conditions such as inflammatory disease, liver disease, renal anemia, chronic anemia and thalassemia as well as fetal distress in utero. Newborns were divided correspondingly into offspring observation and control groups.

\section{Detection methods}

In order to detect $\mathrm{Hb}$, sTfR, serum ferritin (SF) and erythropoietin (E-PO), $5 \mathrm{~mL}$ venous blood was drawn from each pregnant woman that participated in the study, and $5 \mathrm{~mL}$ umbilical arterial blood was drawn from the newborn infant of the corresponding woman. Periodic physical examinations were carried out respectively for infants at birth, 42 days, 4 months, and 6 months after birth. Peripheral blood levels of Hb and sTfR were detected for the infants at 6 months of age.

\section{Instruments and reagents}

Routine blood examination was carried out using the MEK-5108K automatic hematology analyzer (CELLTAC, Japan). SF detection was performed using the SF kit (BeckmanCoulter, U.S.A.); sTfR detection was performed using an enzyme-linked immunoassay kit (R\&D Systems, USA).

\section{Diagnostic criteria}

Diagnostic criteria for pregnant women, newborns, and infants, respectively, were: $\mathrm{Hb}$ $<100 \mathrm{~g} / \mathrm{L} ; \mathrm{Hb}<145 \mathrm{~g} / \mathrm{L} ;$ and $\mathrm{Hb}<110 \mathrm{~g} / \mathrm{L}$. Diagnostic values of sTfR were: IDA $7.22 \pm 4.42$ $\mathrm{mg} / \mathrm{L}$; SID $2.39 \pm 0.81 \mathrm{mg} / \mathrm{L}$; and normal $1.41 \pm 0.29 \mathrm{mg} / \mathrm{L}$ (Lee et al., 2006). 


\section{Statistical methods}

The SPSS v.19.0 software was used for data analysis. The count data were analyzed by chi-square test; the measurement data were analyzed by the Student $t$-test, and $\mathrm{P}<0.05$ was considered to be statistically significant.

\section{RESULTS}

\section{Comparison of blood levels of $\mathrm{Hb}$, sTfR, SF, and E-PO in pregnant women, new- borns, and 6-month-old infants between observation and control groups}

There were significant differences in venous blood levels of $\mathrm{Hb}$, sTfR, SF and E-PO in pregnant women between observation and control groups $(\mathrm{P}<0.01)$ (Table 1); there were significant differences in peripheral blood levels of $\mathrm{Hb}$ and sTfR in 6-month-old infants between the two groups $(\mathrm{P}<0.01)$ (Table 2). The results showed that in addition to Hb, sTfR and SF had great implications for the diagnosis of IDA. There was no significant difference in levels of $\mathrm{Hb}$, sTfR, SF and E-PO in neonatal umbilical arterial blood between the two groups $(\mathrm{P}>0.05)$. The aforementioned 3 indexes in umbilical arterial blood had a larger range of fluctuation, and there was a difference in the numerical values between the two groups, but no statistical difference (Table 3).

Table 1. Comparison of Hb, sTfR and SF levels among pregnant women.

\begin{tabular}{lcccc}
\hline Group & Cases & $\mathrm{Hb}(\mathrm{g} / \mathrm{L})$ & $\mathrm{sTfR}(\mathrm{mg} / \mathrm{L})$ & $\mathrm{SF}(\mathrm{ng} / \mathrm{mL})$ \\
\hline Observation & 70 & $98.04 \pm 8.91$ & $3.54 \pm 0.63$ & $11.73 \pm 8.91$ \\
Control & 70 & $122.58 \pm 11.53$ & $1.74 \pm 0.94$ & $27.98 \pm 12.87$ \\
\hline
\end{tabular}

$\mathrm{Hb}=$ hemoglobin; sTfR $=$ soluble transferrin receptor; $\mathrm{SF}=$ serum ferritin.

Table 2. Comparison of $\mathrm{Hb}$, sTfR and SF levels among newborns.

\begin{tabular}{lcccr}
\hline Group & Cases & $\mathrm{Hb}(\mathrm{g} / \mathrm{L})$ & $\mathrm{sTfR}(\mathrm{mg} / \mathrm{L})$ & $\mathrm{SF}(\mathrm{ng} / \mathrm{mL})$ \\
\hline Observation & 70 & $157.23 \pm 23.59$ & $3.69 \pm 1.01$ & $142.57 \pm 32.64$ \\
Control & 70 & $172.97 \pm 19.57$ & $2.01 \pm 1.59$ & $175.09 \pm 25.79$ \\
\hline
\end{tabular}

$\mathrm{Hb}=$ hemoglobin; sTfR $=$ soluble transferrin receptor; $\mathrm{SF}=$ serum ferritin.

Table 3. Comparison of $\mathrm{Hb}$ and sTfR levels among 6-month-old infants.

\begin{tabular}{lccr}
\hline Group & Cases & $\mathrm{Hb}(\mathrm{g} / \mathrm{L})$ & $\mathrm{sTfR}(\mathrm{mg} / \mathrm{L})$ \\
\hline Observation & 70 & $107.58 \pm 16.75$ & $5.79 \pm 2.01$ \\
Control & 70 & $116.89 \pm 27.91$ & $3.90 \pm 1.82$ \\
\hline
\end{tabular}

$\mathrm{Hb}=$ hemoglobin; sTfR $=$ soluble transferrin receptor; $\mathrm{SF}=$ serum ferritin.

\section{Spearman correlation analysis}

The occurrence of anemia in 6-month-old infants was highly correlated to factors such as blood levels of $\mathrm{Hb}$, sTfR, and SF of the mother during pregnancy adding egg yolks, 
and mashed fruits and vegetables at 4 months after birth; and the sTfR levels in 6-month-old infants $(\mathrm{r}=0.412,0.208,0.307,0.112,0.457,0.507,0.324 ; \mathrm{P}<0.01)$; and it had a correlation with SF levels in newborns $(\mathrm{r}=0.352 ; \mathrm{P}<0.05)$; but it had no correlation with neonatal $\mathrm{Hb}$ and sTfR levels, birth weight, gender, height, feeding patterns, adding rice flour, egg yolks, and mashed fruits and vegetables during 4 to 6 months after birth $(\mathrm{P}>0.05)$.

\section{Detection rate of IDA in 6-month-old infants is significantly higher in the observation group}

The study showed that 43 IDA infants were detected among 6-month-old infants delivered by women with anemia during pregnancy $(61.43 \%)$, and 16 were born by healthy pregnant women $(22.86 \%)$, a statistically significant difference (chi-square $=14.98 ; \mathrm{P}<0.01)$.

\section{DISCUSSION}

Results of this study suggest significant differences in $\mathrm{Hb}$ and sTfR levels of pregnant women and their 6-month-old infants compared with controls $(\mathrm{P}<0.01)$; however, there was no significant difference in newborns between the two groups $(\mathrm{P}>0.05)$. Moreover, the IDA detection rate of 6-month-old infants was $61.43 \%$ in the observation group and $22.86 \%$ in the control group $(\mathrm{P}<0.01)$. Thus, it is evident that the health of infants with IDA correlates with maternal anemia during pregnancy. However, infant anemia can be prevented by following various initiatives.

\section{Anemia during pregnancy is one of the major factors leading to IDA in 6-month-old infants}

In the long-term scientific research, it has been postulated that severe iron deficiency among pregnant women could lead to iron deficiency among infants, due to lack of congenital fetal iron storage; research also confirms that the iron storage of a healthy, full-term infant could sustain its growth for up to 6 months (Masutomi et al., 2004). The results of this study confirmed that it was also possible to induce infant IDA at the age of 6 months, even if the mother had mild IDA during pregnancy.

\section{Prevention and treatment of iron deficiency during pregnancy have important implications for reducing iron deficiency in infants}

In the present study, it was found that maternal iron metabolism status has an important effect on iron storage status in the fetal liver, because within 1 to 2 years after the birth of the infant, about 40 to $70 \%$ of iron in newly generated $\mathrm{Hb}$ is taken up from the maternal body during fetal development; the maternal provision of iron can be up to 375-475 $\mathrm{mg}$ to meet the growth needs of the fetus, placenta and umbilical cord during pregnancy (Zanardo et al., 2005; Rizvi et al., 2007). If the mother has an iron deficiency during pregnancy, this condition can cause an adverse iron deficiency loop; that is to say, iron deficiency in pregnant women can lead to subsequent iron deficiency in infants that can persist into adolescence and adulthood (Thomas et al., 2003). Therefore, monitoring the iron content of the body is extremely important for early diagnosis and treatment, which can play a significant role in both blocking the iron deficiency loop between mother and infant and in reducing the incidence of IDA (Willian 
and Bertil, 2002; McAdams et al., 2008).

\section{Screening indexes must be determined as soon as possible for early screening of iron deficiency}

China promulgated the "Recommendations for Prevention and Treatment of Iron Deficiency and Iron Deficiency Anemia in Children" in 2008, which emphasizes a need to perform timely intervention for early iron deficiency in infants. That is, although juvenile discovery is difficult, making a definitive diagnosis in the obviously abnormal SID period, in addition to performing routine physical examinations, can effectively reduce the incidence of IDA (Alverson et al., 1988). In China's traditional diagnostic index for SID, the common methods for measurement of transferrin saturation and free erythrocyte protoporphyrin are more complicated, and thus are rarely used. Currently, the standard for detection of storage iron content is still the invasive bone marrow iron stain examination (von Tempelhoff et al., 2008; Lloreda-García et al., 2012), but its compliance is not high when used in the early diagnosis of IDA. Common clinical detection methods also have several disadvantages (Svare et al., 2006): the stability of serum iron is poor, and transferrin is a negative acute phase reactant, the content of which is decreased to varying degrees when the body is infected or when liver and kidney function is impaired. Currently, the SF index is recognized as the most sensitive index for reflecting iron storage content. It can generate a precise response to the decreased stored iron content of the body in the ID period, but it is also an acute phase protein and is therefore susceptible to effects of the body, such as inflammation, tumor growth, and particular physiological states such as pregnancy, lactation, and the infant growth period (Kling et al., 1996; Schwarz et al., 2005).

\section{In modern medicine, sTfR is becoming a new and extremely important scientific index for monitoring of iron storage status of the body and screening of iron deficiency}

The rising phenomenon of sTfR can supplement the deficiency of SF by occurring in the ID period of iron deficiency, and by showing a significantly progressive rise with the aggravated degree of iron deficiency (Ganzevoort et al., 2007; Kayastha and Tuladhar, 2007; Kondrackiene et al., 2007).Therefore, sTfR can be used as a reliable detection index in IDE and IDA periods. sTfR can respond well to the erythropoietic capacity and iron deficiency status of the body, and thus, can be used to determine SID (Katsinelos et al., 2006). Compared to traditional biochemical indexes of iron status, sTfR has the following advantages: it is highly specific and sensitive; is less susceptible to interference of body inflammation and underlying acute and chronic infection; has biological stability; lacks a correlation between concentration and age; and is unaffected by pregnancy and other chronic diseases. The experimental operation is simple, as all that is needed for detection is a small amount of serum and a sample of finger blood. The sTfR level detected in finger blood is highly related to that in venous blood (Zanardo et al., 2005; Ness and Catov, 2007). The clinical practical value of sTfR is immense, and the prospect of its promotion is considerable; it can be used as an extremely important index of IDA during pregnancy as well as for in-clinic detection of IDA and for evaluation of treatment efficacy (Nomura, 2004; Widness, 2008). Detection of sTfR levels in peripheral blood is particularly suitable for monitoring the treatment efficacy of IDA in pediatric clinics. For instance, it is possible to circumvent several non-standard phenomena of diagnostic and treatment processes, such as previous lack of diag- 
nosis or treatment of early SID, inadequate treatment of IDA, insufficient amount of medication, and non-complemented in vivo iron storage.

In summary, for neonatal anemia, early diagnosis and treatment should be carried out. Method of detection plays an important role in early diagnosis; therefore, we should strengthen the study of detection methods in clinical treatment, as only the use of an advanced detection method can effectively prevent and treat neonatal anemia.

\section{Conflicts of interest}

The authors declare no conflict of interest.

\section{ACKNOWLEDGMENTS} (\#201440).

Research supported by the Hunan Province Key Discipline Construction Funding

\section{REFERENCES}

Alverson DC, Isken VH and Cohen RS (1988). Effect of booster blood transfusions on oxygen utilization in infants with bronchopulmonary dysplasia. J. Pediatr. 113: 722-726.

Cogswell ME, Parvanta I, Ickes L, Yip R, et al. (2003). Iron supplementation during pregnancy, anemia, and birth weight: a randomized controlled trial. Am J. Clin. Nutr. 78: 773-781.

Emamghorashi F and Heidari T (2004). Iron status of babies born to iron-deficient anaemic mothers in an Iranian hospital. East Mediterr. Health J. 10: 808-814.

Ganzevoort W, Rep A, De Vries JI, Bonsel GJ, et al. (2007). Relationship between thrombophilic disorders and type of severe early-onset hypertensive disorder of pregnancy. Hypertens. Pregnancy 26: 433-445.

Geelhoed D, Agadzi F, Visser L, Ablordeppey E, et al. (2006). Maternal and fetal outcome after severe anemia in pregnancy in rural Ghana. Acta Obstet. Gynecol. Scand. 85: 49-55.

Grjibovski A, Bygren LO, Svartbo B and Magnus P (2004). Housing conditions, perceived stress, smoking, and alcohol: determinants of fetal growth in Northwest Russia. Acta Obstet. Gynecol. Scand. 83: 1159-1166.

Katsinelos P, Paroutoglou G, Kountouras J, Zavos C, et al. (2006). Efficacy and safety of therapeutic ERCP in patients 90 years of age and older. Gastrointest. Endosc. 63: 417-423.

Kayastha S and Tuladhar H (2007). Study of low birth weight babies in Nepal Medical College. Nepal Med. Coll. J. 9: 266-269.

Kling PJ, Schmidt RL, Roberts RA and Widness JA (1996). Serum erythropoietin levels during infancy: associations with erythropoiesis. J. Pediatr. 128: 791-796.

Kondrackiene J, Beuers U, Zalinkevicius R, Tauschel HD, et al. (2007). Predictors of premature delivery in patients with intrahepatic cholestasis of pregnancy. World J. Gastroenterol 13: 6226-6230.

Lee HS, Kim MS, Kim MH, Kim YJ, et al. (2006). Iron status and its association with pregnancy outcome in Korean pregnant women. Eur. J. Clin. Nutr. 60: 1130-1135.

Lloreda-García JM, Castellanos JL and Sánchez JS (2012). A preterm infant with anaemia and left leg mild hemihypertrophy (discussion and diagnosis). Acta Paediatr. 101: 1270-1271.

Masutomi N, Shibutani M, Takagi H, Uneyama C, et al. (2004). Dietary influence on the impact of ethinylestradiol-induced alterations in the endocrine/reproductive system with perinatal maternal exposure. Reprod. Toxicol 18: 23-33.

McAdams RM, Dotzler SA, Winter LW and Kerecman JD (2008). Severe hemolytic disease of the newborn from anti-e. J. Perinatol. 28: 230-232.

Ness RB and Catov J (2007). Invited commentary: Timing and types of cardiovascular risk factors in relation to offspring birth weight. Am J. Epidemiol. 166: 1365-1367.

Nomura H, Tanimoto H, Kajiwara E, Shimono J, et al. (2004). Factors contributing to ribavirin-induced anemia. $J$. Gastroenterol. Hepatol. 19: 1312-7.

Rizvi SA, Hatcher J, Jehan I and Qureshi R (2007). Maternal risk factors associated with low birth weight in Karachi: a case-control study. East Mediterr. Health J. 13: 1343-1352. 
Schwarz KB, Dear PR, Gill AB, Newell SJ, et al. (2005). Effects of transfusion in anemia of prematurity. Pediatr. Hematol. Oncol. 22: 551-559.

Svare JA, Schmidt H, Hansen BB and Lose G (2006). Bacterial vaginosis in a cohort of Danish pregnant women: prevalence and relationship with preterm delivery, low birthweight and perinatal infections. BJOG 113: 1419-1425.

Thomas A, Mathew M, Unciano Moral E and Vaclavinkova V (2003). Acute massive fetomaternal hemorrhage: case reports and review of the literature. Acta Obstet. Gynecol. Scand 82: 479-480.

von Tempelhoff GF, Heilmann L, Rudig L, Pollow K, et al. (2008). Mean maternal second-trimester hemoglobin concentration and outcome of pregnancy: a population-based study. Clin. Appl. Thromb. Hemost. 14: 19-28.

Widness JA (2008). Pathophysiology of Anemia During the Neonatal Period, Including Anemia of Prematurity. Neoreviews. 9: e520.

Willian C and Bertil E (2002). Avery's Disease of the newborn. 7th edn. Harcourt Publishers Limited, Harcourt.

Zanardo V, Savio V, Sabrina G, Franzoi M, et al. (2005). The effect of pre-eclampsia on the levels of coagulation and fibrinolysis factors in umbilical cord blood of newborns. Blood Coagul Fibrinolysis 16: 177-181. 